\title{
Indications for the Appropriate Use of Damage Control Surgery and Damage Control Interventions in Civilian Trauma Patients
}

\author{
Derek J Roberts MD PhD ${ }^{1,2}$, Juan Duchesne MD³, Megan L Brenner MD MS ${ }^{4}$, \\ Bruno Pereira MD5 ${ }^{5}$, Bryan A Cotton MD MPH ${ }^{6}$, Andrew W Kirkpatrick MD MHSc ${ }^{7,8}$ \\ and Mansoor Khan MBBS PhD ${ }^{9}$ for the Damage Control Resuscitation Committee* \\ 'Division of Vascular and Endovascular Surgery, Department of Surgery, University of Ottawa and The Ottawa Hospital \\ Research Institute, The Ottawa Hospital, Ottawa, Ontario, Canada \\ ${ }^{2} T$ The O'Brien Institute for Public Health, University of Calgary, Calgary, Alberta, Canada \\ ${ }^{3}$ Department of Surgery Tulane, New Orleans, Louisiana, USA \\ ${ }^{4}$ Department of Surgery, University of California Riverside, Riverside, California, USA \\ ${ }^{5}$ Department of Surgery and Surgical Critical Care, University of Campinas, Campinas, Brazil \\ ${ }^{6}$ Department of Surgery, University of Texas Health Science Center, Houston, Texas, USA \\ 'Regional Trauma Services and the Departments of Surgery and Critical Care Medicine, University of Calgary, Calgary, Alberta, Canada \\ ${ }^{8}$ Canadian Forces Health Services, Canada \\ ${ }^{9}$ Academic Department of Military Surgery and Trauma, Royal Centre for Defence Medicine, UK
}

\begin{abstract}
In patients undergoing emergent operation for trauma, surgeons must decide whether to perform a definitive or damage control (DC) procedure. DC surgery (abbreviated initial surgery followed by planned reoperation after a period of resuscitation in the intensive care unit) has been suggested to most benefit those injured patients more likely to succumb to the "vicious cycle" of hypothermia, acidosis and coagulopathy, and/or postoperative abdominal compartment syndrome (ACS) than the failure to complete all organ repairs. However, currently there exists no unbiased evidence to support that DC surgery benefits injured patients. Further, the procedure is associated with substantial morbidity, long durations of intensive care unit and hospital stay, increased healthcare resource utilization, and possibly a reduced quality of life among survivors. Therefore, it is important to ensure that DC laparotomy is only utilized in situations where the expected procedural benefits are predicted to outweigh the expected procedural harms. In this manuscript, we review the comparative effectiveness and safety of DC surgery when used for different procedural indications. We also review recent studies suggesting variation in use of DC surgery between trauma centers and the potential harms associated with overuse of the procedure. We also review published consensus indications for the appropriate use of DC surgery and specific abdominal, pelvic, and vascular DC interventions in civilian trauma patients. We conclude by providing recommendations as to how the above list of published appropriateness indications may be used to reduce overuse of DC surgery and guide medical and surgical education, quality improvement, and surgical practice.
\end{abstract}

Keywords: Damage Control Surgery; Damage Control Interventions; Indications; Wounds and Injuries

\footnotetext{
*Damage Control Resuscitation Committee

Derek J. Roberts MD PhD, Juan Duchesne MD,

Megan L. Brenner MD MS, Bruno Pereira MD,

Bryan A. Cotton MD MPH, Andrew W. Kirkpatrick MD MHSc, Mansoor Khan MBBS PhD, Paula Ferrada MD,

Tal M. Hörer MD PhD, David Kauvar MD,

Carlos Ordonez MD, Artai Priouzram MD
}

\author{
Corresponding author: \\ Derek J Roberts MD PhD FRCSC, Division of Vascular and \\ Endovascular Surgery, Department of Surgery, University of \\ Ottawa, The Ottawa Hospital, Civic Campus, Room A280, 1053 \\ Carling Avenue, Ottawa, Ontario, Canada, K1Y 4E9. \\ Email: Derek.Roberts01@gmail.com \\ (C) 2021 CC BY-NC 4.0 - in cooperation with Depts. of \\ Cardiothoracic/Vascular Surgery, General Surgery and Anesthesia, \\ Örebro University Hospital and Örebro University, Sweden
}




\section{INTRODUCTION}

In patients undergoing emergent operation for trauma, surgeons must decide whether to perform a definitive or damage control (DC) procedure [1-4]. In contrast to definitive laparotomy, DC laparotomy includes an abbreviated initial operation that aims to rapidly control the "compelling source" of hemorrhage and/or contamination using what Feliciano originally termed "rapid conservative operative techniques" (now also referred to as DC interventions) [5-8]. The patient is subsequently admitted to the intensive care unit (ICU) after temporary abdominal closure (TAC) for ongoing resuscitation before returning to the operating room for additional surgery and/or primary abdominal fascial closure (i.e., fascia-to-fascia re-approximation within the index hospitalization) $[1,5,6]$.

DC surgery has been suggested to most benefit injured patients more likely to die from physiological exhaustion secondary to the "vicious cycle" of hypothermia, acidosis and coagulopathy, and/or postoperative abdominal compartment syndrome (ACS) than the failure to complete all organ repairs $[6,9,10]$. However, currently there exists no unbiased, randomized evidence to support that DC surgery significantly benefits injured patients $[1,5]$. Further, the procedure is associated with substantial morbidity, long lengths of ICU and hospital stay, increased healthcare resource utilization, and possibly a reduced quality of life among survivors [11-15].

Therefore, it is important to ensure that DC surgery is only utilized in situations where the expected procedural benefits are predicted to outweigh the expected procedural harms [2,3]. However, several studies have reported that the procedure may presently be overused $[3,16,17]$, which is concerning as overuse of DC laparotomy has increasingly been reported to be associated with increased morbidity and mortality $[18,19]$. Our group has therefore suggested that injured patient outcomes may improve with more selective use of DC laparotomy [2-4].

In this article, we review the comparative effectiveness and safety of DC versus definitive trauma surgery when used for different procedural indications. We also review studies that suggest significant variation in use of DC laparotomy among trauma centers and the potential harm associated with overuse of the procedure. Finally, we review results of recent studies conducted by the Indications for Trauma Damage Control Surgery International Study Group. Their work created a list of preand intraoperative clinical scenarios that nine experts in trauma surgery and a large cohort of surgeons who regularly operate on injured patients in level-1 to -3 trauma centers agreed appropriately indicated use of DC surgery in civilian trauma patients $[1-4,6]$. We conclude by providing recommendations on how to use the above list of published appropriateness indications to reduce overuse of DC surgery and guide medical and surgical education, quality improvement, future research, and surgical practice.

\section{COMPARATIVE EFFECTIVENESS AND SAFETY OF TRAUMA DC SURGERY}

Although one study began enrolling patients as early as 2016, to date no randomized controlled trial (RCT) that compares DC and definitive surgery in trauma patients has been completed [1,20,21]. A Cochrane systematic review of DC laparotomy for abdominal trauma conducted in 2012 identified a small number of observational studies and no RCTs [1,21]. In June 2016, Harvin et al. began enrolling patients aged 16 years or older undergoing emergent laparotomy (defined as admission directly to the operating room from the emergency department within 90 min of arrival) into a pragmatic, single-center, parallel group, pilot RCT comparing DC and definitive laparotomy [20]. Inclusion criteria require that the attending surgeon must believe that one or more predefined potential indications for DC laparotomy exist [20]. Results of this RCT were originally expected in 2020.

Another systematic review conducted by our group in 2018 identified two cohort studies [22,23] that evaluated outcomes associated with implementation or utilization of indications for DC surgery [24]. Rice et al. reported that, when compared with minor deviations, moderate or major deviations from a protocol that suggested using DC surgery for patients with a temperature $<35^{\circ} \mathrm{C}$, lactate $>4 \mathrm{mmol} / \mathrm{L}$ (or greater than twice the upper limit of normal), or corrected $\mathrm{pH}<7.3$ were independently associated with a significantly reduced survival at 90 days [22,24]. Asensio et al. developed a guideline that suggested use of DC surgery in patients who received more than $4 \mathrm{~L}$ of packed red blood cells (PRBCs), more than $5 \mathrm{~L}$ of PRBCs and whole blood combined, or a total operating room fluid (PRBCs and whole blood, other blood products, and crystalloid) volume replacement of more than $12 \mathrm{~L}$; had a temperature $<34^{\circ} \mathrm{C}$, serum [HCO3-] $\leq 15 \mathrm{mEq} / \mathrm{L}$, or arterial $\mathrm{pH} \leq 7.2$ during operation; were found to have a thoracic or abdominal vascular injury or complex hepatic injury requiring packing; required emergency department or operating room thoracotomy; or developed intraoperative coagulopathy or dysrhythmias [23,24]. In this study, use of this guideline was associated with a significantly decreased unadjusted odds of intra-abdominal abscesses, extra-abdominal infections, and abdominal fistulae; a significantly increased unadjusted odds of abdominal closure; and significantly reduced unadjusted lengths of ICU and hospital stay [23,24].

We also identified 14 other cohort studies [18,19, 25-36] that compared outcomes of patients treated with DC versus definitive laparotomy in different clinical situations [24]. Stone et al., Rotondo et al., and Chinnery et al. reported a significant improvement in unadjusted survival with use of DC or staged laparotomy instead of definitive laparotomy for those that developed a coagulopathy during operation, received 


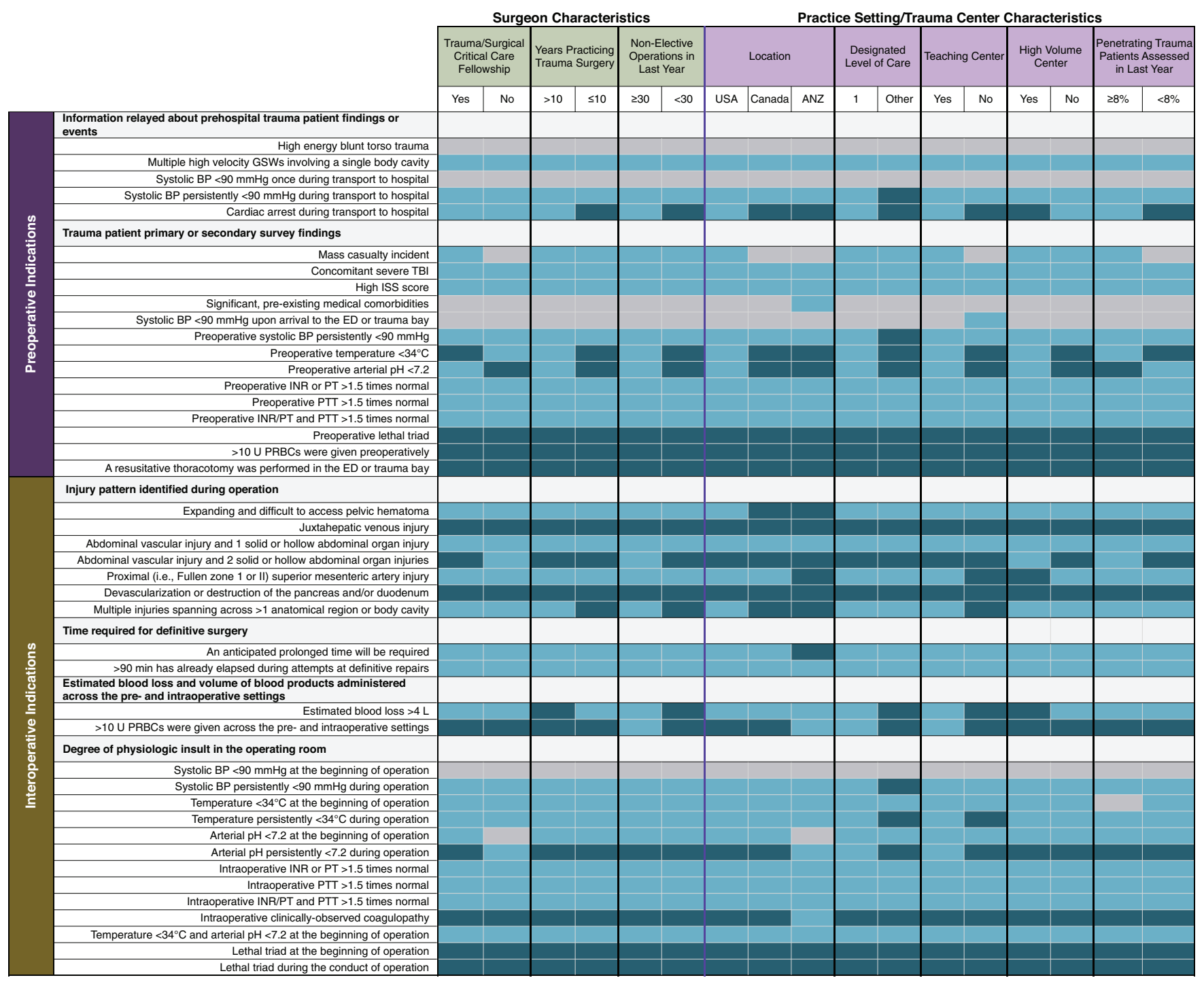

Key to Color Coding of Appropriateness Ratings

Significant benefit (median Likert scale rating $=5$, without disagreement)

Benefit (median Likert scale rating $=4$, without disagreement)

Uncertain (median Likert scale rating $=3$, without disagreement)

Figure 1 Color map of respondents' appropriateness ratings of published candidate pre- and intraoperative indications for use of damage control surgery stratified by surgeon- and trauma center-level characteristics. ANZ indicates Australia and New Zealand

(i.e., Australasia); BP, blood pressure; ED, emergency department; GSWs, gunshot wounds; INR, international normalized ratio; ISS, injury severity scale; PT, prothrombin time; PTT, partial thromboplastin time. Interpolated median values halfway between two integers were rounded up. Disagreement was defined as at least 33\% of respondents rating the indication as 1-2 (significant harm-harm) on the Likert Scale and at least another 33\% rating it 4-5 (benefit-significant benefit). Figure and Figure legend reprinted from reference [4], copyright (2016), with permission from Elsevier. The Creative Commons license does not apply to this content. Use of the material in any format is prohibited without written permission from the publisher, Elsevier.

more than $10 \mathrm{U}$ PRBCs and had one or more major abdominal vascular and two or more abdominal visceral injuries, or had combined abdominal vascular and pancreas gunshot injuries, respectively [25-27]. However, because the type of surgery (DC or definitive laparotomy) for the patients enrolled in these and the other 11 cohort studies identified by the systematic review mentioned above were not randomly assigned, these studies are likely confounded by indication [6]. This confounding occurs because surgeons choose to perform DC laparotomy based on patient, provider, and hospital characteristics, and these characteristics likely influence outcomes [37].

Therefore, very little valid or unbiased observational studies exist to support use of DC over definitive surgery in different clinical situations.

\section{VARIATION IN AND POTENTIAL OVERUSE OF TRAUMA DC LAPAROTOMY BETWEEN CENTERS}

Several authors have recently reported data suggesting that a variation in use of DC laparotomy may exist 


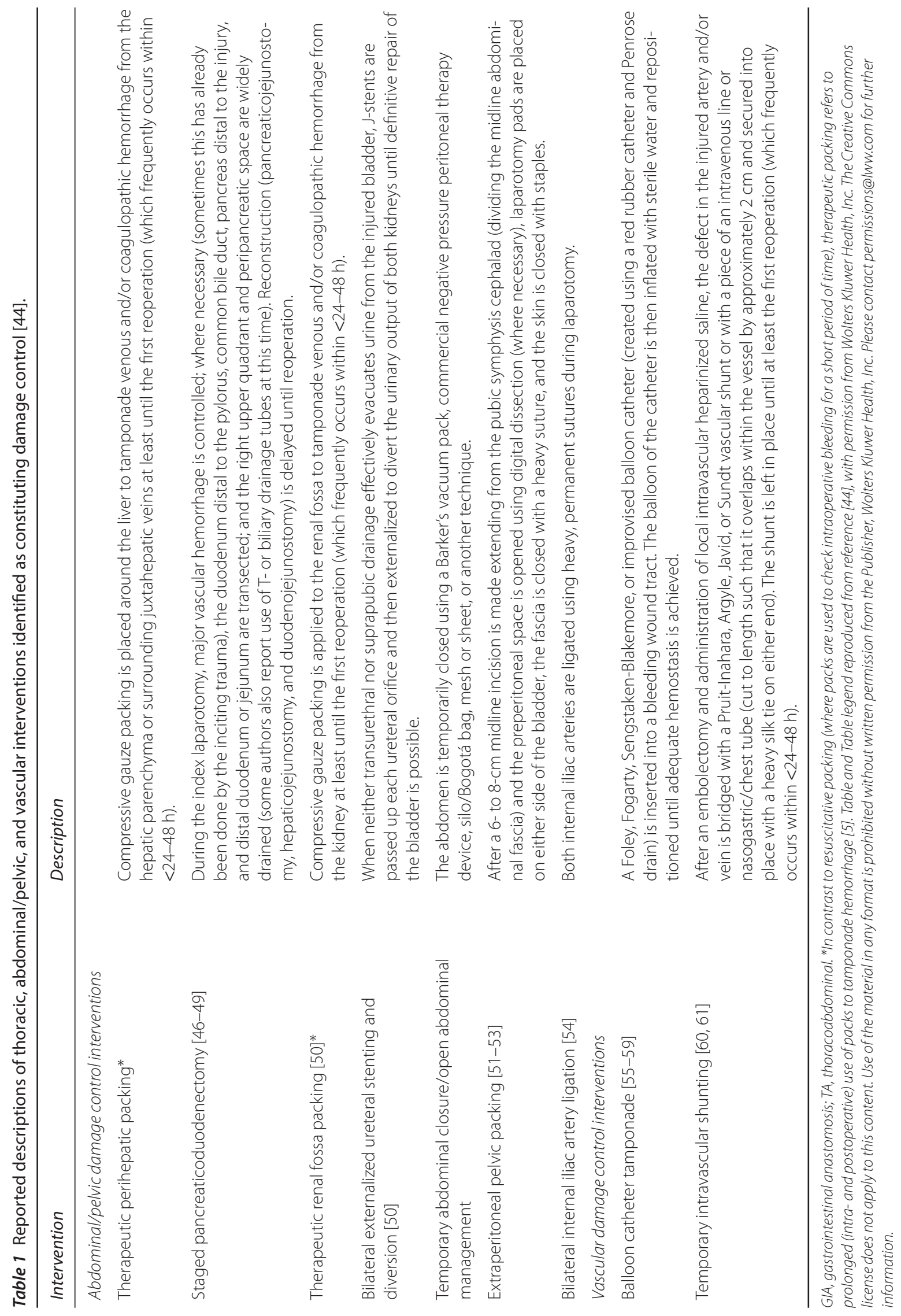


Table 2 Highest rated candidate indications for use of damage control surgery in civilian trauma patients.

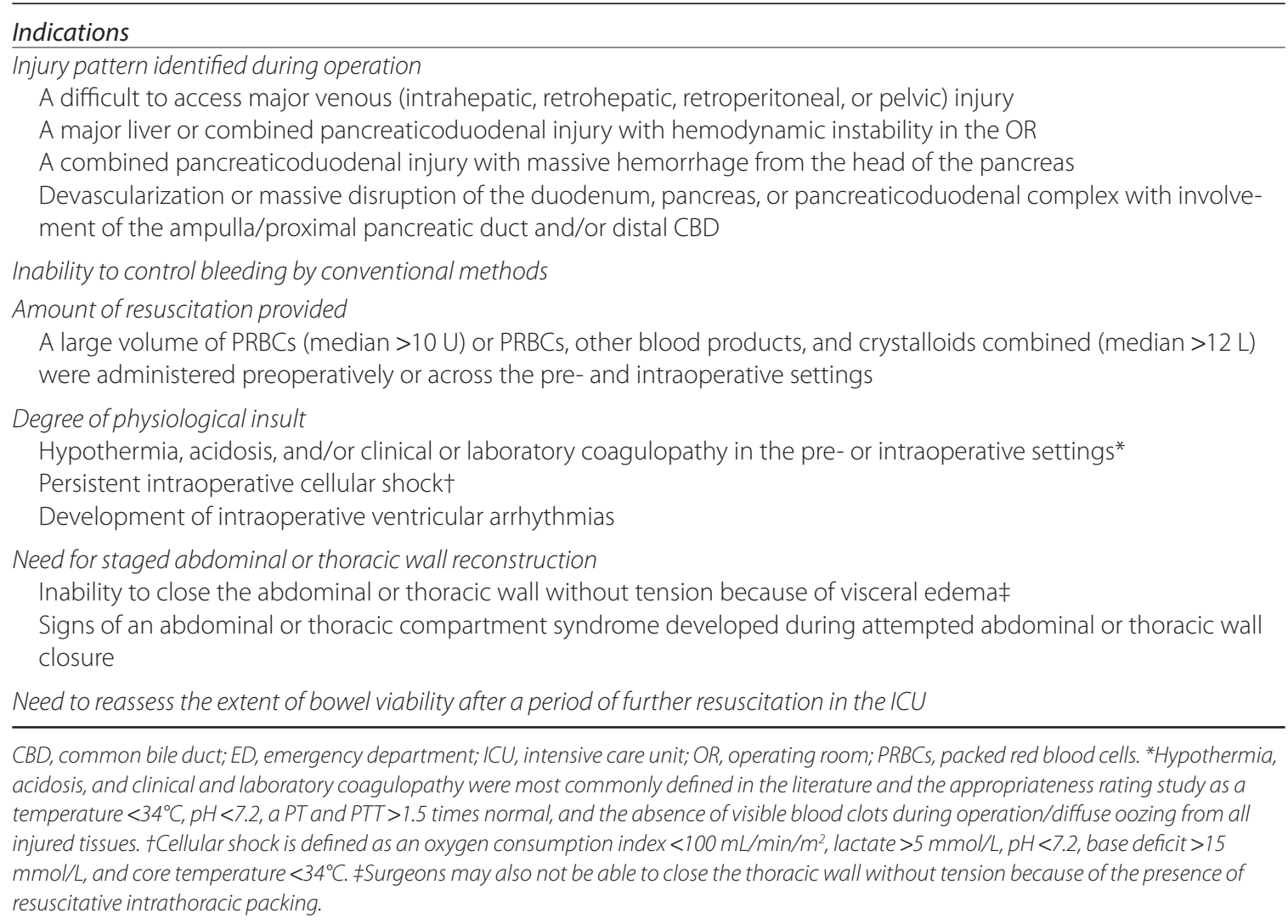

among trauma centers or that the procedure may currently be overused $[3,4,6]$. In a recently reported posthoc analysis of the PROPPR randomized trial, DC surgery was used for $33 \%$ to $83 \%$ of patients requiring urgent laparotomy across 12 of the participating institutions [38]. Interestingly, although there was no significant adjusted mortality difference among these centers, the unadjusted risk of sepsis and ventilator-associated pneumonia was higher among those treated with DC laparotomy [38]. Therefore, some have suggested that decreasing use of DC among individual trauma centers may not necessarily influence injured patient mortality but may decrease their morbidity [38].

Variation in use of DC across trauma centers could relate to increasing use of the procedure for indications other than those previously suggested to be appropriate or validated in the literature $[1,6,24]$. In support of this, one retrospective cohort study by Hatch et al. reported that one in five patients who received DC laparotomy at a level-1 trauma center between 2004 and 2008 failed to have at least one traditional indication for use of the procedure $[1,6,39]$. In this study, only $33 \%$ of the patients who underwent DC laparotomy were acidotic, $43 \%$ hypothermic, and $48 \%$ coagulopathic on arrival at the ICU after operation [1,6,24,39]. Although the ideal rate of use of DC during emergent laparotomy is presently unknown, it was estimated in one cohort study to range between $19 \%$ and $27 \%$ across six American, level-1 trauma centers [40].
Some evidence suggests that overuse of DC laparotomy may be associated with increased morbidity and mortality $[3,4,18,19,39,41]$. Martin et al. reported that, when compared with patients with a severe abdominal injury who underwent therapeutic definitive laparotomy, use of DC laparotomy in patients with an arrival systolic blood pressure $(\mathrm{BP})>90 \mathrm{mmHg}$, no severe traumatic brain injury (TBI) (head Abbreviated Injury Scale score <3), and no combined abdominal injuries was independently associated with significantly increased odds of major postoperative complications and a significantly increased adjusted length of hospital stay [18]. In another propensity-matched cohort study, Harvin et al. reported that use of DC instead of definitive laparotomy [for intra-abdominal packing $(68 \%)$, second-look laparotomy (6\%), hemodynamic instability $(15 \%)$, to expedite postoperative care or intervention $(8 \%)$, abdominal compartment syndrome prophylaxis $(1 \%)$, contamination $(1 \%)$, or other/unclear reasons $(1 \%)$ ] was associated with a significantly increased incidence of gastrointestinal (GI) ileus and bleeding, abdominal fascial dehiscence, superficial surgical site infection (SSI), and death [19]. Finally, in a follow-up study by Harvin et al. in 2019, injured patients who underwent DC laparotomy across six American, level-1 trauma centers and were judged by majority faculty vote to have been candidates for definitive laparotomy were matched 1:1 with those who underwent definitive trauma laparotomy at these centers using propensity scores [42]. In this study, for those whom surgeons had equipoise 
Table 3 Indications for use of thoracic, abdominal/pelvic, and vascular damage control interventions that were rated to be appropriate by a panel of experts.*

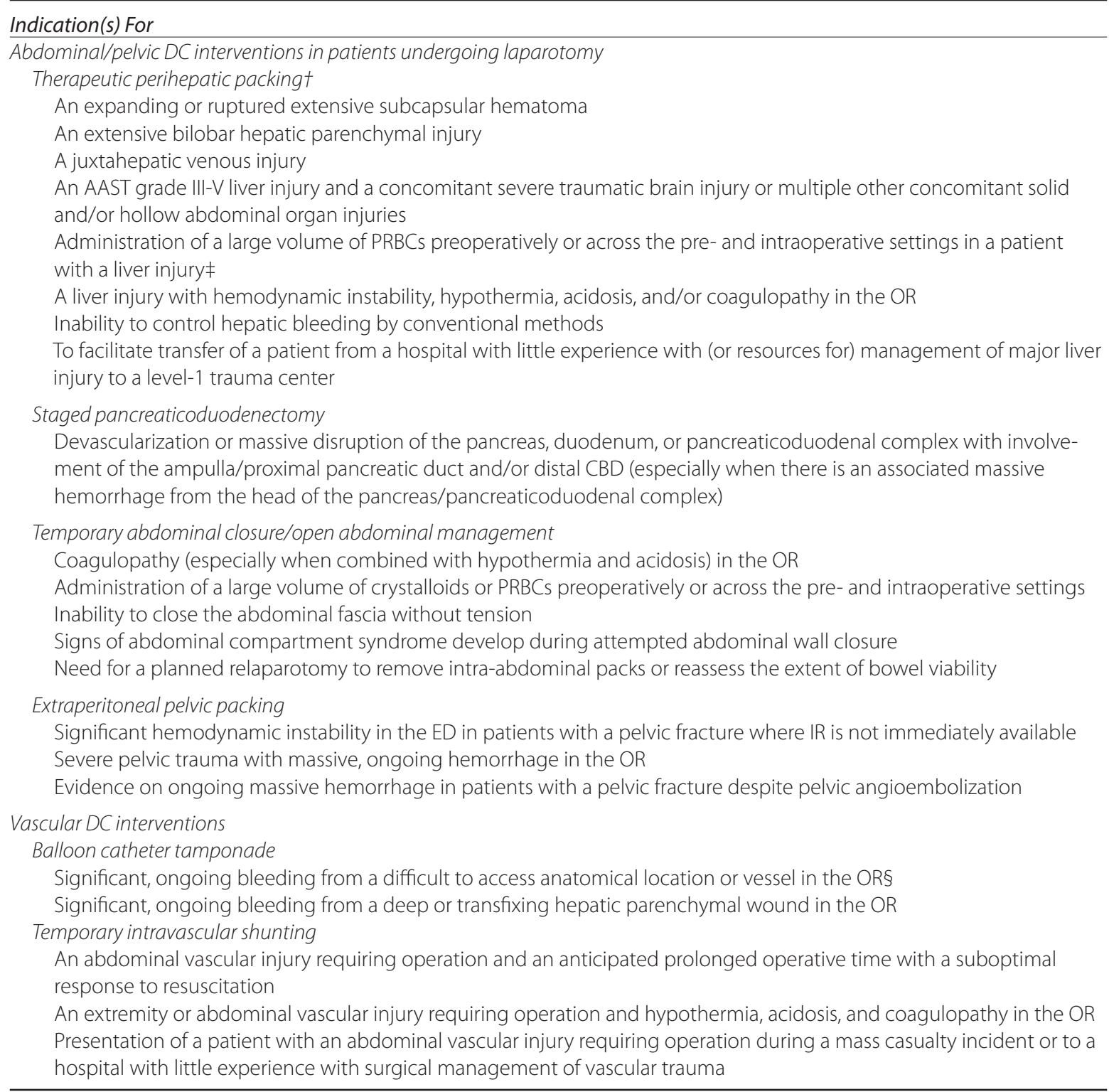

$C B D$, common bile duct; $D C$, damage control; ED, emergency department; IR, interventional radiology; $O R$, operating room; $P R B C S$, packed red blood cells. *Hypothermia, acidosis, and coagulopathy have most commonly been defined in the peer-reviewed literature as a temperature $<34, \mathrm{pH}<7.2$, and a PT or PTT >1.5 times normal and the absence of visible blood clots during operation/diffuse oozing from all injured tissues [3]. †In contrast to resuscitative packing (where packs are used to check intraoperative bleeding for a short period of time), therapeutic packing refers to prolonged (intra- and postoperative) use of packs to tamponade hemorrhage [5]. \#A large volume of PRBCs was most often defined in the literature as $>10$ or $>12.5$ units. \$Difficult-to-access anatomical locations have been reported to include the head, zone III of the neck, the angle of the mandible, and the trunk; while difficult-to-access vessels have been reported to include the carotid artery behind the pharynx, the carotid artery or internal jugular vein at the base of the skull, the internal maxillary artery, the second, third, and fourth portions of the vertebral artery, and the distal branches of the internal iliac artery in the pelvis. Reproduced with permission from reference [44], with permission from Wolters Kluwer Health, Inc. The Creative Commons license does not apply to this content. Use of the material in any format is prohibited without written permission from the Publisher, Wolters Kluwer Health, Inc. Please contact permissions@/ww.com for further information.

regarding use of DC or definitive laparotomy, definitive laparotomy was associated with a significantly higher probability of fewer hospital-free, ventilator-free, and ICU-free days, suggesting that use of definitive laparotomy in this setting may decrease hospital resource utilization [42]. However, the two groups demonstrated a similar probability of major abdominal complications [42].

\section{PUBLISHED APPROPRIATENESS INDICATIONS FOR USE OF DC SURGERY AND DC INTERVEN- TIONS IN CIVILIAN TRAUMA PATIENTS}

We previously hypothesized that variation in use of DC surgery among trauma centers may occur when surgeons are uncertain which operative profile is best across the large number of varying clinical situations encountered 
in practice $[4,6,43,44]$. This uncertainty is likely exacerbated by the limited available data evaluating the effectiveness and safety of DC surgery and DC interventions and the risks of bias associated with existing evidence on the topic $[4,6,43,44]$. Further, conducting RCTs evaluating DC laparotomy is difficult for many reasons, most importantly the lack of equipoise among surgeons regarding its likely superior outcomes when used instead of definitive laparotomy in certain clinical situations (e.g., a juxtahepatic venous injury) [45]. Despite this, however, surgeons must decide when to use DC (or specific DC interventions) over definitive surgery (or specific definitive surgical interventions) in their practices [6,44].

In 2013, Roberts et al. and the Indications for Trauma Damage Control Surgery International Study Group began a program of research to develop evidenceinformed indications for the appropriate use of DC surgery and DC interventions in civilian trauma patients $[1-5,44]$. We first conducted a scoping review that aimed to identify a comprehensive list of the reported indications for use of DC surgery and DC interventions and examine the content and evidence on which these indications were based $[2,24,44]$. An indication was defined as "a clinical finding/scenario that advised use of DC surgery (or a DC intervention) over definitive surgery (or a definitive surgical intervention)" [3]. This study identified 270 peer-reviewed articles that reported 1,107 indications for DC surgery and 424 indications for 16 different DC interventions (see Table 1 for our previously published definitions of abdominal, pelvic, and vascular DC interventions) [2,24,46-61]. Of note, bilateral internal iliac artery ligation should only be performed in carefully selected patients, given the risk of pelvic ischemia associated with this intervention (which may lead to bilateral buttock claudication or necrosis, vasculogenic impotence, colorectal ischemia or necrosis, and spinal cord injury).

We subsequently conducted a qualitative content analysis to synthesize the above published indications into 123 codes representing uniquely reported indications for DC surgery and 101 codes representing uniquely reported indications for 16 different DC interventions [3, 44]. An international panel of nine different trauma surgery experts located in the United States $(n=3)$, Canada $(n=1)$, the United Kingdom $(n=1)$, Finland $(n=1)$, Australia $(n=1)$, and South Africa $(n=2)$ then rated 101 $(82 \%)$ of the unique indications for DC surgery and 78 $(77 \%)$ of the unique indications for DC interventions to be appropriate for use in surgical practice $[3,44]$. The highest rated indications for DC surgery and those rated to be appropriate for the individual DC interventions are listed in Table 2 and Table 3, respectively [3,44].

We then surveyed the opinions of 366 surgeons who regularly treat injured patients in the United States, Canada, Australia, and New Zealand on the appropriateness of many of the indications for DC surgery rated in the previous expert appropriateness rating study [4]. Of the 366 surveyed surgeons, $201(56 \%)$ responded and rated $15(78.9 \%)$ preoperative and $23(95.8 \%)$ intraoperative indications to be appropriate for use in their practices [4]. Ratings of appropriateness were consistent across subgroups of surgeons with different training, experience, and practice settings, suggesting that practicing surgeons have relatively consistent opinions regarding use of DC surgery in certain clinical scenarios (see Figure 1 for a color map of respondents' appropriateness ratings reported in this study stratified by surgeon- and trauma center-level characteristics) [4]. Nearly $90 \%$ of the respondents also agreed that injured patients who present with physiological derangements that significantly improve or reverse during operation were candidates for definitive instead of DC laparotomy [4].

As the above studies did not measure how surgeons actually practiced, their assessments of appropriateness may have reflected idealized practices $[4,62]$. We therefore recently reported the results of a study that sought to determine the accuracy of the above-published appropriateness indications for predicting use of DC surgery among patients undergoing emergent laparotomy at a large, level-1 trauma center in the United States [62]. In this study, two published preoperative indications (a systolic BP persistently $<90 \mathrm{mmHg}$ or core body temperature $<34^{\circ} \mathrm{C}$ ) produced moderate changes in the pre-test probability of patients undergoing DC laparotomy [62]. Five published intraoperative indications produced large and often conclusive changes in the pre-test probability of conducting DC during emergent laparotomy, including the finding of a devascularized or completely disrupted pancreas, duodenum, or pancreaticoduodenal complex during operation; an estimated intraoperative blood loss greater than $4 \mathrm{~L}$; administration of more than 10 U PRBCs in the pre- and/or intraoperative period; and a systolic BP persistently $<90 \mathrm{mmHg}$ or arterial $\mathrm{pH}$ persistently $<7.2$ during operation [62]. Many of the indications that produced large shifts in the pre-test probability of conducting DC laparotomy were uncommonly encountered in practice (i.e., their incidence was $<2 \%$ ) [62]. Finally, a small number of published appropriateness indications were independently associated with the conduct of DC laparotomy even after adjusting for the simultaneous presence of other indications, suggesting that some surgeons may choose to conduct the procedure when they encounter certain single clinical findings [62].

\section{IMPLICATIONS OF RECENT RESEARCH AND RECOMMENDATIONS}

In recent years, wide variation has been reported in the rates of use of DC laparotomy among North American trauma centers $[3,16,17]$. This variation may be explained by several factors, including differences in surgeon equipoise regarding the benefit of the procedure 


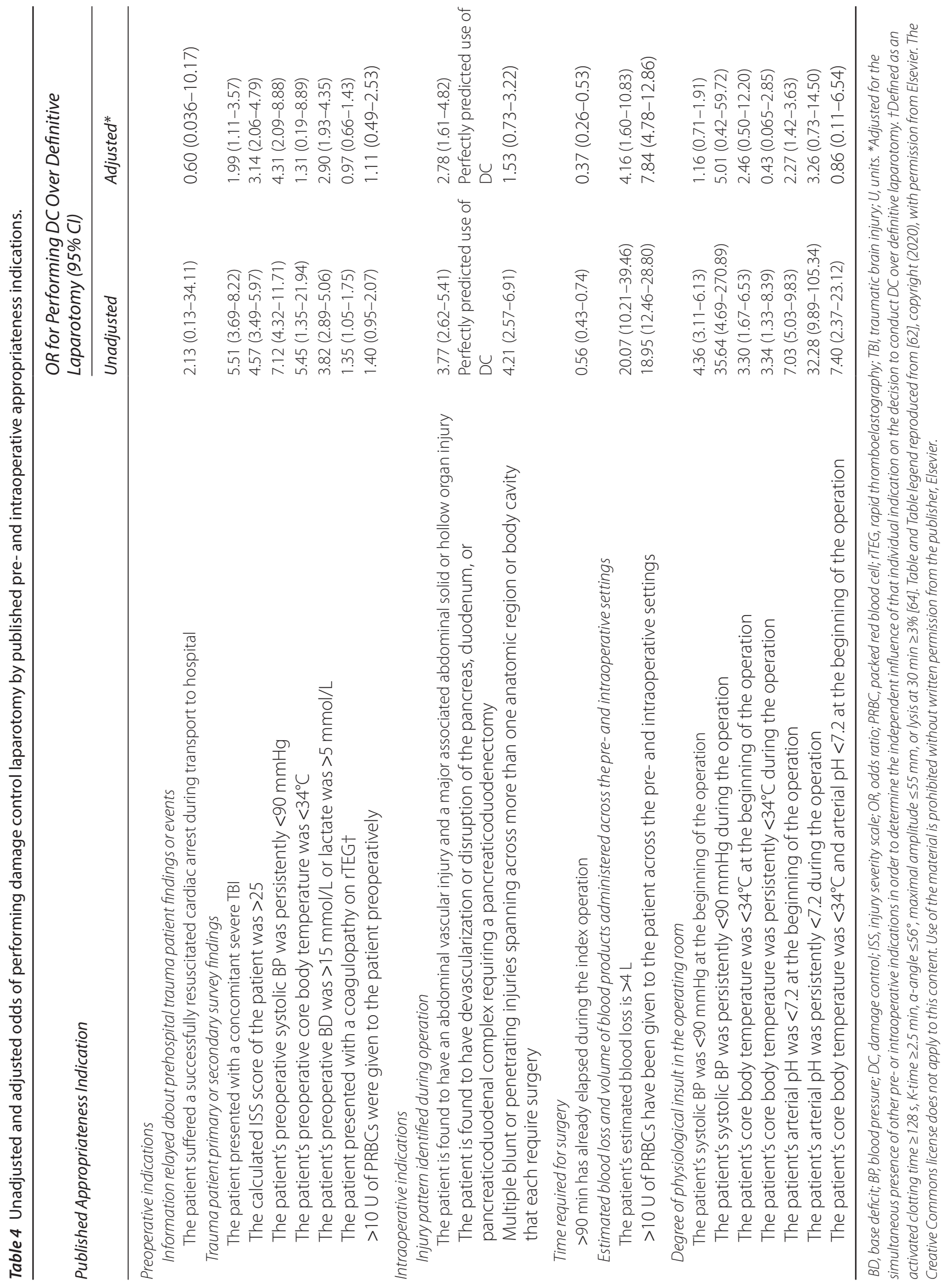


in different clinical situations and the lack of valid data supporting that DC laparotomy improves survival in severely injured patients. The possible overuse of DC laparotomy across these trauma centers is concerning as some recent data suggest that when DC is used instead of definitive laparotomy in patients in whom surgeons have equipoise between the two, use of DC laparotomy is associated with increased resource utilization [42]. Other studies have also suggested that use of DC instead of definitive laparotomy when DC laparotomy is not indicated may be associated not only with increased resource utilization, but with higher morbidity and possibly mortality $[18,19]$.

Table 4 summarizes those published indications that have been rated to be appropriate for use in practice by experts and practicing surgeons [62]. We also provide estimates of the unadjusted and adjusted (i.e., adjusted for the simultaneous presence of the other indications listed in the table) odds of undergoing DC laparotomy for each of these different indications [62]. Although the intraoperative findings of an expanding or difficult-to-access pelvic hematoma or juxtahepatic venous injury were previously rated to be appropriate indications for use of DC laparotomy in our expert appropriateness rating study [3] and cross-sectional survey of practicing surgeons [4], we do not yet have data on their ability to predict use of the procedure in practice [62]. Despite this, experts and practicing surgeons strongly suggest using DC surgery in these situations.

The indications listed in Table 4 may be used to educate surgical trainees on the appropriate, yet limited use of DC laparotomy and guide trauma center quality improvement practices aimed at reducing inappropriate use of the procedure. The group at the Red Duke Trauma Institute at Memorial Hermann Hospital-Texas Medical Center recently reported a decrease in the rate of use of DC laparotomy from 39\% between 2011 and 2013 to $23 \%$ between 2013 and 2015 using a multifaceted quality improvement initiative that included audit and feedback for every DC laparotomy case [63]. The indications listed in Table 4 may also be used to guide the development of prospective observational and randomized studies aimed at understanding in which clinical situations DC laparotomy may offer a survival benefit over definitive laparotomy in injured patients. In our opinion, it is now time for these studies to be conducted.

\section{CONCLUSIONS}

Although DC surgery may benefit select, critically injured patients, it may currently be overused in some trauma centers. This is concerning as some studies have reported that overuse of this technique may be associated with increased healthcare utilization, morbidity, and potentially mortality. The published DC surgery appropriateness indications outlined in this manuscript may be used to reduce overuse of DC surgery and guide medical and surgical education, quality improvement, future research, and surgical practice.

\section{Ethics Statement}

(1) All the authors mentioned in the manuscript have agreed to authorship, read and approved the manuscript, and given consent for submission and subsequent publication of the manuscript.

(2) The authors declare that they have read and abided by the JEVTM statement of ethical standards including rules of informed consent and ethical committee approval as stated in the article.

\section{Conflicts of Interest}

The authors declare that they have no conflicts of interest.

\section{Funding}

Dr. Roberts' research is supported by funding from the Department of Surgery, University of Ottawa, Ottawa, Ontario, Canada.

\section{Author Contributions}

All authors have contributed to the writing and editing of this manuscript.

\section{REFERENCES}

[1] Roberts DJ, Zygun DA, Kirkpatrick AW, Ball CG, Faris $\mathrm{PD}$, Bobrovitz N, et al. A protocol for a scoping and qualitative study to identify and evaluate indications for damage control surgery and damage control interventions in civilian trauma patients. BMJ Open. 2014;4(7):e005634.

[2] Roberts DJ, Bobrovitz N, Zygun DA, Ball CG, Kirkpatrick AW, Faris PD, et al. Indications for use of damage control surgery and damage control interventions in civilian trauma patients: a scoping review. J Trauma Acute Care Surg. 2015;78(6):1187-96.

[3] Roberts DJ, Bobrovitz N, Zygun DA, Ball CG, Kirkpatrick AW, Faris PD, et al. Indications for Use of Damage Control Surgery in Civilian Trauma Patients: A Content Analysis and Expert Appropriateness Rating Study. Ann Surg. 2016;263(5):1018-27.

[4] Roberts DJ, Zygun DA, Faris PD, Ball CG, Kirkpatrick AW, Stelfox HT. Opinions of practicing surgeons on the appropriateness of published indications for use of damage control surgery in trauma patients: an international crosssectional survey. J AmColl Surg. 2016;223(3):515-29.

[5] Roberts DJ, Ball CG, Feliciano DV, Moore EE, Ivatury RR, Lucas CE, et al. History of the Innovation of Damage Control for Management of Trauma Patients: 19022016. Ann Surg. 2017;265(5):1034-44.

[6] Roberts DJ. Applications of damage control surgery in modern civilian trauma care. In: Duchesne J, Inaba K, Khan M, editors. Damage Control in Trauma Care: An 
Evolving Comprehensive Team Approach. Springer International Publishing; 2018. pp. 9-24.

[7] Feliciano DV, Burch JM, Spjut-Patrinely V, Mattox KL, Jordan GL, Jr. Abdominal gunshot wounds. An urban trauma center's experience with 300 consecutive patients. Ann Surg. 1988;208(3):362-70.

[8] Rotondo MF, Zonies DH. The damage control sequence and underlying logic. Surg Clin North Am. 1997;77(4):761-77.

[9] Ball CG. Damage control surgery. Curr Opin Crit Care. 2015;21(6):538-43.

[10] Roberts DJ, Ball CG, Kirkpatrick AW. Increased pressure within the abdominal compartment: intra-abdominal hypertension and the abdominal compartment syndrome. Curr Opin Crit Care. 2016;22(2):174-85.

[11] Miller RS, Morris JA, Jr., Diaz JJ, Jr., Herring MB, May AK. Complications after 344 damage-control open celiotomies. J Trauma. 2005;59(6):1365-74.

[12] Montalvo JA, Acosta JA, Rodriguez P, Alejandro K, Sarraga A. Surgical complications and causes of death in trauma patients that require temporary abdominal closure. Am Surg. 2005;71(3):219-24.

[13] Sutton E, Bochicchio GV, Bochicchio K, Rodriguez ED, Henry S, Joshi M, et al. Long term impact of damage control surgery: a preliminary prospective study. J Trauma. 2006;61(4):831-6.

[14] Cheatham ML, Safcsak K, Llerena LE, Morrow CE, Jr., Block EF. Long-term physical, mental, and functional consequences of abdominal decompression. J Trauma. 2004;56(2):237-42.

[15] Codner PA, Brasel KJ, Deroon-Cassini TA. Staged abdominal repairs reduce long-term quality of life. Injury. 2012;43(9):1513-6.

[16] Higa G, Friese R, O’Keeffe T, Wynne J, Bowlby P, Ziemba M, et al. Damage control laparotomy: a vital tool once overused. J Trauma. 2010;69(1):53-9.

[17] Cotton BA, Reddy N, Hatch QM, LeFebvre E, Wade CE, Kozar RA, et al. Damage control resuscitation is associated with a reduction in resuscitation volumes and improvement in survival in 390 damage control laparotomy patients. Ann Surg. 2011;254(4):598605.

[18] Martin MJ, Hatch Q, Cotton B, Holcomb J. The use of temporary abdominal closure in low-risk trauma patients: helpful or harmful? J Trauma Acute Care Surg. 2012;72(3):601-8.

[19] Harvin JA, Wray CJ, Steward J, Lawless RA, McNutt MK, Love JD, et al. Control the damage: morbidity and mortality after emergent trauma laparotomy. Am J Surg. 2016;212(1):34-9.

[20] Harvin JA, Podbielski J, Vincent LE, Fox EE, Moore LJ, Cotton BA, et al. Damage control laparotomy trial: design, rationale and implementation of a randomized controlled trial. Trauma Surg Acute Care Open. 2017;2(1):e000083.

[21] Cirocchi R, Montedori A, Farinella E, Bonacini I, Tagliabue L, Abraha I. Damage control surgery for abdominal trauma. Cochrane Database Systematic Rev. 2013(3):CD007438.

[22] Rice TW, Morris S, Tortella BJ, Wheeler AP, Christensen MC. Deviations from evidence-based clinical management guidelines increase mortality in critically injured trauma patients*. Crit Care Med. 2012;40(3): 778-86.

[23] Asensio JA, McDuffie L, Petrone P, Roldan G, Forno W, Gambaro E, et al. Reliable variables in the exsanguinated patient which indicate damage control and predict outcome. Am J Surg. 2001;182(6): 743-51.

[24] Roberts DJ, Bobrovitz N, Zygun DA, Kirkpatrick AW, Ball CG, Faris PD, Stelfox HT. Indications for trauma damage control surgery international study group. Evidence for use of damage control surgery and damage control interventions in civilian trauma patients: a systematic review. World J Emerg Surg. In Press.

[25] Stone HH, Strom PR, Mullins RJ. Management of the major coagulopathy with onset during laparotomy. Ann Surg. 1983;197(5):532-5.

[26] Rotondo MF, Schwab CW, McGonigal MD, Phillips GR, 3rd, Fruchterman TM, Kauder DR, et al. 'Damage control': an approach for improved survival in exsanguinating penetrating abdominal injury. $\mathrm{J}$ Trauma. 1993;35(3):375-83.

[27] Chinnery GE, Krige JE, Kotze UK, Navsaria P, Nicol A. Surgical management and outcome of civilian gunshot injuries to the pancreas. Br J Surg. 2012;99 Suppl $1: 140-8$.

[28] Ordonez C, Garcia A, Parra MW, Scavo D, Pino LF, Millan M, et al. Complex penetrating duodenal injuries: less is better. J Trauma Acute Care Surg. 2014;76(5): 1177-83.

[29] Thompson CM, Shalhub S, DeBoard ZM, Maier RV. Revisiting the pancreaticoduodenectomy for trauma: a single institution's experience. J Trauma Acute Care Surgery. 2013;75(2):225-8.

[30] Mayberry J, Fabricant L, Anton A, Ham B, Schreiber M, Mullins R. Management of full-thickness duodenal laceration in the damage control era: evolution to primary repair without diversion or decompression. Am Surg. 2011;77(6):681-5.

[31] Liu QW, Zhou BJ, Qin HX, Sun K. [Application of damage control surgery for severe abdominal trauma]. Zhonghua wei chang wai ke za zhi = Chin J Gastrointestinal Surg. 2011;14(7):506-8.

[32] Yu BQ, Hu HB, Li M, Wang Y, Han KW, Su JC, et al. [Strategy and analysis of early management on ninety multiple trauma patients]. Zhonghua wai ke za zhi [Chin J Surgery]. 2009;47(20):1550-2.

[33] MacKenzie S, Kortbeek JB, Mulloy R, Hameed SM. Recent experiences with a multidisciplinary approach to complex hepatic trauma. Injury. 2004;35(9): 869-77.

[34] Apartsin KA, Stifutkin AV, Rasulov RI, Grigor'ev EG. [Staged correction of surgical pathology of the stomach ("Damage Control") in conditions of decompensated hypovolemic shock]. Vestnik khirurgii imeni I I Grekova. 2002;161(2):102-5.

[35] Carrillo EH, Spain DA, Wilson MA, Miller FB, Richardson JD. Alternatives in the management of penetrating injuries to the iliac vessels. J Trauma. 1998;44(6): 1024-30.

[36] Carmona RH, Peck DZ, Lim RC, Jr. The role of packing and planned reoperation in severe hepatic trauma. J Trauma. 1984;24(9):779-84. 
[37] Sox HC, Goodman SN. The methods of comparative effectiveness research. Annu Rev Public Health. 2012;33:425-45.

[38] Watson JJ, Nielsen J, Hart K, Srikanth P, Yonge JD, Connelly CR, et al. Damage control laparotomy utilization rates are highly variable among level I trauma centers: pragmatic, randomized optimal platelet and plasma ratios findings. J Trauma Acute Care Surg. 2017;82(3):481-8.

[39] Hatch QM, Osterhout LM, Podbielski J, Kozar RA, Wade CE, Holcomb JB, et al. Impact of closure at the first take back: complication burden and potential overutilization of damage control laparotomy. J Trauma. 2011;71(6):1503-11.

[40] Harvin JA, Sharpe JP, Croce MA, Goodman MD, Pritts TA, Dauer ED, et al. Better understanding the utilization of damage control laparotomy: a multi-institutional quality improvement project. J Trauma Acute Care Surg. 2019;87(1):27-34.

[41] Hatch QM, Osterhout LM, Ashraf A, Podbielski J, Kozar RA, Wade CE, et al. Current use of damage-control laparotomy, closure rates, and predictors of early fascial closure at the first take-back. J Trauma. 2011;70(6):1429-36

[42] Harvin JA, Sharpe JP, Croce MA, Goodman MD, Pritts TA, Dauer ED, et al. Effect of damage control laparotomy on major abdominal complications and lengths of stay: a propensity score matching and Bayesian analysis. J Trauma Acute Care Surg. 2019;87(2):282-8.

[43] Birkmeyer JD, Reames BN, McCulloch P, Carr AJ, Campbell WB, Wennberg JE. Understanding of regional variation in the use of surgery. Lancet. 2013; 382(9898):1121-9.

[44] Roberts DJ, Bobrovitz N, Zygun DA, Ball CG, Kirkpatrick AW, Faris PD, et al. Indications for use of thoracic, abdominal, pelvic, and vascular damage control interventions in trauma patients: a content analysis and expert appropriateness rating study. J Trauma Acute Care Surg. 2015;79(4):568-79.

[45] Roberts DJ, Zygun DA, Ball CG, Kirkpatrick AW, Faris PD, James MT, et al. Challenges and potential solutions to the evaluation, monitoring, and regulation of surgical innovations. BMC Surgery. 2019;19(1):119.

[46] Ivatury RR, Nassoura ZE, Simon RJ, Rodriguez A. Complex duodenal injuries. Surg Clin North Am. 1996;76(4):797-812.

[47] Carrillo C, Fogler RJ, Shaftan GW. Delayed gastrointestinal reconstruction following massive abdominal trauma. J Trauma. 1993;34(2):233-5.

[48] Eastlick L, Fogler RJ, Shaftan GW. Pancreaticoduodenectomy for trauma: delayed reconstruction: a case report. J Trauma. 1990;30(4):503-5.

[49] Koniaris LG, Mandal AK, Genuit T, Cameron JL. Twostage trauma pancreaticoduodenectomy: delay facilitates anastomotic reconstruction. J Gastrointestinal Surg: official journal of the Society for Surgery of the Alimentary Tract. 2000;4(4):366-9.

[50] Coburn M. Damage control for urological injuries. Surg Clin North Am. 1997;77(4):821-34.
[51] Ertel W, Keel M, Eid K, Platz A, Trentz O. Control of severe hemorrhage using C-clamp and pelvic packing in multiply injured patients with pelvic ring disruption. J Orthop Trauma. 2001;15(7):468-74.

[52] Smith WR, Moore EE, Osborn P, Agudelo JF, Morgan SJ, Parekh AA, et al. Retroperitoneal packing as a resuscitation technique for hemodynamically unstable patients with pelvic fractures: report of two representative cases and a description of technique. J Trauma. 2005;59(6):1510-4.

[53] Cothren CC, Osborn PM, Moore EE, Morgan SJ, Johnson JL, Smith WR. Preperitonal pelvic packing for hemodynamically unstable pelvic fractures: a paradigm shift. J Trauma. 2007;62(4):834-42.

[54] DuBose J, Inaba K, Barmparas G, Teixeira PG, Schnuriger $\mathrm{B}$, Talving $\mathrm{P}$, et al. Bilateral internal iliac artery ligation as a damage control approach in massive retroperitoneal bleeding after pelvic fracture. J Trauma. 2010; 69(6):1507-14.

[55] Morimoto RY, Birolini D, Junqueira AR, Jr., Poggetti R, Horita LT. Balloon tamponade for transfixing lesions of the liver. Surg Gynecol Obstet. 1987; 164(1):87-8.

[56] Poggetti RS, Moore EE, Moore FA, Mitchell MB, Read RA. Balloon tamponade for bilobar transfixing hepatic gunshot wounds. J Trauma. 1992;33(5):694-7.

[57] Feliciano DV, Burch JM, Mattox KL, Bitondo CG, Fields G. Balloon catheter tamponade in cardiovascular wounds. Am J Surg. 1990;160(6):583-7.

[58] Gilroy D, Lakhoo M, Charalambides D, Demetriades D. Control of life-threatening haemorrhage from the neck: a new indication for balloon tamponade. Injury. 1992;23(8):557-9.

[59] Ball CG, Wyrzykowski AD, Nicholas JM, Rozycki GS, Feliciano DV. A decade's experience with balloon catheter tamponade for the emergency control of hemorrhage. J Trauma. 2011;70(2):330-3.

[60] Ding W, Wu X, Li J. Temporary intravascular shunts used as a damage control surgery adjunct in complex vascular injury: collective review. Injury. 2008;39(9): 970-7.

[61] Subramanian A, Vercruysse G, Dente C, Wyrzykowski A, King E, Feliciano DV. A decade's experience with temporary intravascular shunts at a civilian level I trauma center. J Trauma. 2008;65(2):316-26.

[62] Roberts DJ, Stelfox HT, Moore LJ, Cotton BA, Holcomb JB, Harvin JA. Accuracy of published indications for predicting use of damage control during laparotomy for trauma. J Surg Res. 2020;248:45-55.

[63] Harvin JA, Kao LS, Liang MK, Adams SD, McNutt MK, Love JD, et al. Decreasing the use of damage control laparotomy in trauma: a quality improvement project. J Am Coll Surg. 2017;225(2):200-9.

[64] Holcomb JB, Minei KM, Scerbo ML, Radwan ZA, Wade CE, Kozar RA, et al. Admission rapid thrombelastography can replace conventional coagulation tests in the emergency department: experience with 1974 consecutive trauma patients. Ann Surg. 2012;256(3): 476-86. 